\title{
Early Excision and Grafting in Burns: An Experience in a Tertiary Care Industrial Hospital of Eastern India
}

\author{
Prasenjit Goswami ${ }^{1}$ Seelora Sahu ${ }^{2}$ Pankaj Singodia ${ }^{1}$ Manjeet Kumar ${ }^{1}$ Tukulu Tudu ${ }^{1}$ \\ Abinash Kumar ${ }^{1}$ Pankaj Kumar Sinha ${ }^{1}$ \\ ${ }^{1}$ Department of Plastic Surgery and Burns, Tata Main Hospital, \\ Jamshedpur, Jharkhand, India \\ 2 Department of Anesthesiology, Tata Main Hospital, Jamshedpur, \\ Jharkhand, India

\begin{abstract}
Address for correspondence Prasenjit Goswami, MBBS, MS, DNB, MRCS, Department of Plastic Surgery and Burns, Tata Main Hospital, Jamshedpur 831001, Jharkhand, India
\end{abstract} \\ (e-mail: prasenjit_goswami@yahoo.com).
}

Indian J Plast Surg 2019;52:337-342

\begin{abstract}
Introduction To compare the burn patients undergoing early excision and grafting (within 7 days of burn injury) with the patients undergoing late surgeries (more than 7 days after burn injury) to see if there was any difference in surgical and outcome parameters including length of stay, expenditure, and overall outcome of the patients. Material and Methods A retrospective analysis of the data collected from the burn care unit records over a period of one year was done. Fifty-eight patients who matched with our inclusion criteria were divided into two groups. An early excision group who underwent surgery within 7 days of sustaining burn injury $(n=34)$ and a late excision group who underwent excision and grafting/debridement after 7 days of sustaining burn $(n=24)$. Data recorded included demographic variables like age, sex, percentage total body surface area (TBSA) burn; nature of burn; date of sustaining burn; date of admission to the burn care unit; and treatment and outcome parameters like date of surgery, days from burn injury to first surgery, number of surgeries, type of surgery, percentage of TBSA resurfaced with skin graft, blood products used, length of stay, outcome, and total expenditure incurred by patients.

Results There was no statistically significant difference in the number of surgeries done, the units of packed cell used, and the number of fresh frozen plasma (FFP) used between the early excision group and the late excision group. The length of stay was significantly low in the early excision group as compared with the late excision group.

Keywords

- early excision and grafting

- burn patients

- eastern India The expenditure incurred in the treatment of the early excision group was significantly lower than the cost of treatment of the late excision group.

Conclusion Early excision and grafting in burn cases reduces the length of the stay of burn patients and, in turn, reduces the cost of treatment. However, having a dedicated burn care unit is important for the hospitals and both public and private hospitals should make a move in that direction.
\end{abstract}

\section{Introduction}

Burn injury is one of the most devastating forms of injuries and is also one of the biggest health concerns in the developing world. It is a formidable public health issue in terms of mortality, morbidity, and permanent disability. Ninety percent of the burns are reported from low- and middleincome countries (LMIC), of which 50\% are from South and Southeast Asian countries. ${ }^{1}$

The role of early excision and grafting of burns was introduced by Janzekovic way back in $1970^{2}$ and the advantages of the same are well known and have been documented in published online

December 26, 2019
DOI https://doi.org/

10.1055/s-0039-3402707

ISSN 0970-0358.
C2019 Association of Plastic

Surgeons of India
License terms

()(1) $\odot \circledast$ 
various studies. ${ }^{3-7}$ The optimum timing for early excision and grafting is within one week of sustaining burn injury, as reported in various studies. ${ }^{8-14}$ In spite of the known advantages of early excision and grafting, namely, reduction in mortality in patients without inhalation injury and reduction in hospital stay and it being accepted as the standard of practice in all major burn centers around the world, ${ }^{8}$ majority of the hospitals of the LMICs are not in a position of implementing the same as the standard of care for burn patients mainly because of the poor resource settings and patient-related issues. In these hospitals, the traditional method of treating the burn patients with dressings and topical antimicrobial agent is followed until the eschar separates and granulation tissue appears which is then grafted. Patients treated in this manner are prone to infection, sepsis, prolonged hospital stay, hypertrophic scars, and postburn contractures. Although there are studies on early excision and grafting from the developing nations, ${ }^{9,10}$ there is paucity of the number of such studies. Since we have been practicing early excision and grafting at our center from for a long time, we endeavored to compare the patients undergoing early excision and grafting (within 7 days of burn injury) with the patients undergoing late surgeries (more than 7 days after burn injury). This has been done as a preliminary pilot study to see if there was any difference in surgical and outcome parameters including length of stay, expenditure, and overall outcome of the patients. This study is the first of its kind being reported from this region of the country, which makes the study important.

\section{Materials and Methods}

The present study was conducted in a tertiary care industrial hospital of Eastern India. The burn care unit of the hospital caters to the population of East Singhbhum district and also to the people of neighboring districts of Jharkhand and the people from the neighboring states of West Bengal, Bihar, and Odisha. Early excision and grafting were planned in the patients admitted with burns that were fit for surgery and gave consent for surgery. However, early excision was not always possible in many cases and we had to do late surgery because of various reasons like inability to obtain consent for early excision, patient not being fit for anesthesia, and late admission.

A retrospective analysis of the data collected from the burn care unit records over a period of one year from April 2016 to March 2017 was done. Of all the patients admitted during this period, the data of patients who met the inclusion criteria were considered for the analysis. Patients who had deep dermal or full thickness areas in up to $40 \%$ total body surface area (TBSA) burns and underwent surgical excision with skin grafting or debridement were included in the study. As most of the burns had mixed depth, the area of excision and resurfacing was limited to the areas of deep dermal and full thickness burns, which clinically did not have the potential of healing within 3 weeks. The subjective evaluation of the treating surgeons was considered for the extent of excision and grafting. Patients in the extremes of age (younger than 12 years and older than 65 years), those with multiple comorbid conditions, severe inhalation injury, those with burn as a component of multiple trauma, high voltage contact electric burns, and patients with fourth-degree burn were excluded from the study.

As a preliminary study, we took a cutoff as 7 days and we divided the cases into early excision group in whom excision and grafting was done within 7 days of sustaining burns and late excision group in whom the excision was done beyond 7 days of sustaining burns. The data were analyzed for the timing of operation and its relation to the length of stay, outcome, blood product used, and cost of treatment.

All the patients included in the study were resuscitated on arrival in the burn care unit. They received chlorhexidine/cetrimide bath and fluid resuscitation with lactated Ringer's solution according to Parkland's formula. Detailed history was noted and burn evaluation was done in respect to TBSA and depth. Lund and Browder chart was marked and dressing was done in the dressing room with silver sulfadiazine/silver nitrate, Gamjee pads, and bandages. Injectable antibiotics, proton pump inhibitors, and analgesics were started as initial drug therapy. Decision on the operative procedure was taken after the patients are hemodynamically stable.

In all the patients in the early excision group, excision was accompanied with split thickness skin grafting. However, in the late excision group, the skin grafting was not possible to be done in all cases. In those cases where grafting was not possible after excision, only excision was done as the initial operative procedure and these patients required further operations in form of skin grafting on later dates (-Fig. 1).

Data recorded included demographic variables like age, sex, percentage TBSA burnt, and time (in days) from sustaining burn to surgery (-Table $\mathbf{1}$ ).

Treatment and outcome parameters like total percentage of TBSA resurfaced (in \%), blood units used (packed cell), blood units used (fresh frozen plasma [FFP]), length of stay (in days), mean expenditure (in Indian rupees [INR]) ( - Table 2 ).

The primary outcome of our study was the length of hospital stay. The secondary outcome was the expenses included and the overall outcome at the end.

\section{Statistical Analysis}

All the data were analyzed with the aid of SPSS statistical software (version 20, SPSS, Chicago, Illinois). The distribution of the study measurements was verified using Shapiro-Wilk test. Numerical data, such as age and duration of postgraft hospital stay, were expressed as mean \pm standard deviation, while categorical data, such as the sex of patient and number of surgeries required, were expressed as frequencies and percentages. The percentages of various outcome variables were compared by employing chi-square test. Parametric data were analyzed using Student's unpaired $t$-test. Statistical significance was defined at $p<0.05$.

\section{Results}

Of the 335 patients admitted to the burn care unit during the study period, the data of 58 patients met the inclusion 


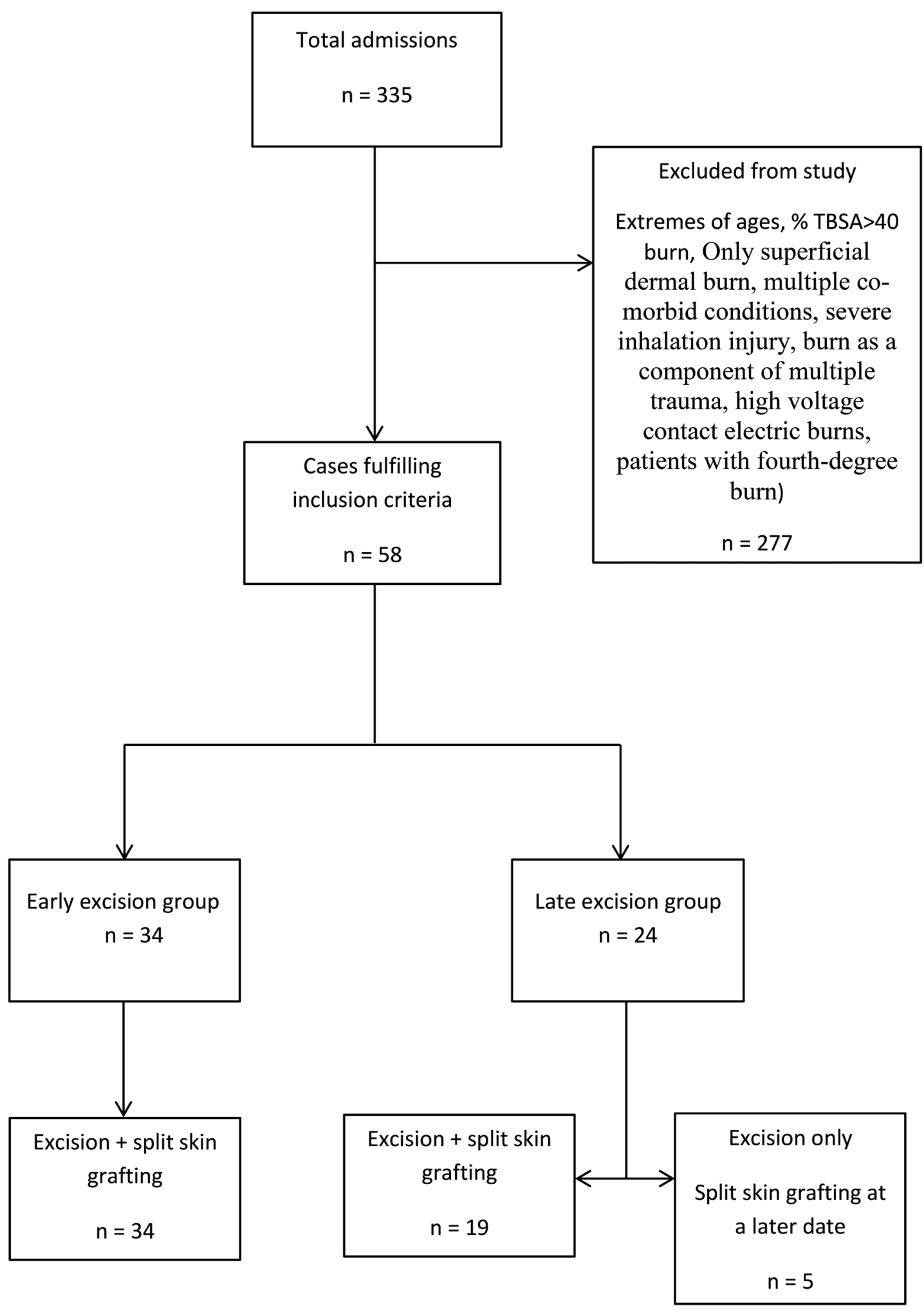

Fig. 1 Flowchart describing the selection of patients for data analysis.

criteria. Of these patients who underwent surgical excision and grafting/debridement, 34 patients met the criteria of early excision while 24 patients underwent delayed excision surgery (-Fig. 1). The reason for delayed surgery was inability to obtain timely consent in 19 cases (79.1\%), 4 cases of late admission (16.6\%), and not getting clearance in preanesthetic checkup in 1 case (4.1\%). The groups did not differ in sex or percentage of TBSA burns but differed in age statistically which has been addressed in limitations of the study (-Table 1). The data were normally distributed for the percentage TBSA ( $p=0.309)$. The distribution was, however, skewed for age $(p=0.015)$ and percentage TBSA resurfaced 
( $p=0.497)$ with maximum number of patients in the age group of 20 to 30 years and maximum number of patients with 8 to $10 \%$ TBSA resurfaced.

In the early excision group, the nature of burns included flame burns in 19 patients, electric burns in 9 patients, contact burns in 3 patients, and scald burns in 3 patients. While in the late excision group, 17 cases had flame burns, 4 cases had electric burns, 2 cases had scald burns, and contact burn in 1 case.

Both the groups received similar resuscitative measures on arrival and were planned for similar surgical procedures. Twenty-four patients could not undergo early excision surgery due to the reasons mentioned earlier. In all the patients in the early excision group, the surgery done was excision and grafting in all the cases. Three patients in this group required two episodes of surgeries (8.82\%).

In the late excision group, excision and grafting was performed in 19 cases and only debridement was performed in 5 cases. One case of excision and skin grafting required 2 surgeries (two episodes of excision and skin grafting in an electrical burn of 35\% TBSA). However, all patients with only debridement required more than 1 surgery (two surgeries in 4 cases and three surgeries in 1 case). Thus, in total, 6 patients in this group required multiple surgeries (25\%). The percentage TBSA resurfaced was comparable between both the groups (-Table 2 ). There was no statistically significant difference between the two groups in terms of the number of surgeries done ( $1.09 \pm 0.28$ times vs. $1.29 \pm 0.55$ times, $p=0.72$ ), the units of packed cell used ( $2.8 \pm 2.7$ units vs. $2.4 \pm 2.2$ units, $p=0.55$ ), and the number of units of FFP used $(2.2 \pm 3.07$ units vs. $2.4 \pm 2.66$ units, $p=0.78)$. Student's $t$-test was used to calculate each of these parameters (- Table 2 ).

The length of stay was significantly low in the early excision group (14.9 \pm 6.37 days vs. $26.4 \pm 20.16$ days, $p=0.003$ ) as compared with the late excision group (-Table 2 ). There was one death in the late excision group which was because the patient unfortunately developed sepsis and multiorgan failure. The expenditure incurred in the treatment of the early excision group was significantly lower than the cost of treatment of the late excision group (INR 100,838 $\pm 46,969$ vs. INR $141,320 \pm 67,220, p=0.009$ ) (-Table 2).

A post hoc analysis of the study group was done using $G$ Power Software. With an effect size of 0.769 and an alpha value of 0.05 for the two groups of sample size 34 (early excision group) and 24 (late excision group), the degree of freedom (df) calculated was 56 with a power of $80.93 \%$.

\section{Discussion}

From the time early excision and grafting of burns were introduced, numerous studies have been done to study the advantages of the same over conventional conservative treatment of burns which involves regular dressings followed by skin grafting only when granulation tissue appears. It has been concluded in many studies that early excision and grafting have various advantages over conventional conservative management of burns which includes decrease in release of inflammatory mediators and bacterial colonization of wounds, which leads to prevention and control of infection, maintenance of form and function, early closure of all wounds, early rehabilitation, decrease in mortality, reduced

Table 1 Demographic parameters, percentage total body surface area burns, and burns to surgery time

\begin{tabular}{|l|l|l|l|}
\hline Variable & $\begin{array}{l}\text { Early excision group } \\
(\boldsymbol{n}=\mathbf{3 4 )}\end{array}$ & $\begin{array}{l}\text { Late excision group } \\
(\boldsymbol{n}=\mathbf{2 4 )}\end{array}$ & $\boldsymbol{p}$ value \\
\hline Age in years & $30.3 \pm 9.73$ & $36.7 \pm 14.50$ & 0.0489 \\
\hline Male patients & 17 & 10 & 0.497 \\
\hline $\begin{array}{l}\text { Total body surface area in percentage } \\
(\%)\end{array}$ & $25.4 \pm 7.82$ & $22.9 \pm 9.15$ & 0.270 \\
\hline Burn to surgery time in days & $5.3 \pm 1.38$ & $14.25 \pm 9.5$ & 0.000 \\
\hline
\end{tabular}

Data expressed as mean \pm standard deviation.

$\mathrm{p}<0.05$ considered significant.

Table 2 Surgical and outcome parameters

\begin{tabular}{|l|l|l|l|}
\hline Variable & Early excision group $(\boldsymbol{n}=34)$ & Late excision group $(\boldsymbol{n}=\mathbf{2 4 )}$ & $\boldsymbol{p}$ value \\
\hline Total percentage of TBSA resurfaced (in \%) & $8.41 \pm 2.78 \%$ & $7.58 \pm 2.68 \%$ & 0.259 \\
\hline Blood units used (packed cell) & $2.8 \pm 2.27$ & $2.4 \pm 2.22$ & 0.55 \\
\hline Blood units used (FFP) & $2.2 \pm 3.07$ & $2.4 \pm 2.62$ & 0.78 \\
\hline Length of stay (in days) & $14.9 \pm 6.37$ & $26.4 \pm 20.16$ & $0.003^{*}$ \\
\hline Mean expenditure (In INR) & $100,837.5 \pm 46,969$ & $141,319.7 \pm 67,220$ & $0.009^{*}$ \\
\hline
\end{tabular}

Abbreviations: FFP, fresh frozen plasma; INR, Indian national rupee; TBSA, total body surface area.

*Statistically significant value.

Data expressed as mean \pm standard deviation.

$p<0.05$ considered significant. 
length of stay, and reduced cost of treatment. Nevertheless, routine early excision and grafting do require a dedicated burn care unit, a dedicated operating theater and time, and a robust blood bank backup.

In developing countries where there is very less numbers of dedicated burn care units, the applicability of early excision and grafting is considered to be limited due to various factors like concerns of pre-existent malnutrition and anemia, inadequate primary resuscitation before arrival at the burn center, decreased ability of the patient to tolerate major surgery and blood loss, and limited availability of skin substitutes, which limits the ability to excise large areas. Owing to these limitations and lack of infrastructure, early excision and grafting have not yet become the standard of care in these countries. ${ }^{9}$

We have a 15-bedded dedicated burn care unit with its operation theater and a state of art blood bank support, but as a trend in developing countries, we also cater to burn patients with various other issues, namely, patients who arrive quite late to our unit, who have not received adequate resuscitation after sustaining burns, who have pre-existing anemia and malnutrition, who have multiple comorbid conditions, and who do not give consent for early excision and grafting. In this study, we have tried to elucidate how the timing of burn surgery is important and compared those patients in whom excision and grafting was done within 7 days of sustaining burn injury compared with those who were operated beyond 7 days. Puri et $\mathrm{al}^{9}$ in their study form Mumbai compared a group of patients who were excised and grafted within 5 days of sustaining burns to a group of patients who were treated conservatively and grafted after 3 weeks or beyond. Gallaher et $\mathrm{a}^{10}$ in their study from the resource poor area in sub-Saharan Africa compared the burn excisions done within 5 days of sustaining burns with those done beyond 5 days.

Owing to the acute blood loss that happens with early excisions, various measures have been adopted during excision like use of tourniquets during limb excisions, infiltration with diluted adrenaline solution, and use of diluted adrenaline swabs to cover the excised region in our cases, we use swabs with adrenaline solution 1:200,000 to control the bleeding. In our study, the use of blood and components was determined by the operative blood loss and postoperative hemoglobin levels. In the early excision cases, on an average 2.8 units of packed cells were used which was not significantly different from late excision cases where a mean of 2.4 units of the same was used. Puri et $\mathrm{al}^{9}$ also compared the transfusion requirement in the early excision group and delayed grafting group and found no significant statistical difference in between them.

Puri et $\mathrm{al}^{9}$ concluded that early excision and grafting decreases the hospital stay of burn patients. Their study observed that it has a definite applicability even in places where the resources might be less than optimal. On the other hand, Gallaher et al, in their study, deciphered that early excision with or without skin grafting, though feasible, are associated with increased mortality. They advocate that delaying the timing of excision and grafting of burn patients in this setting after postburn day 5 may confer a survival advantage. ${ }^{10}$
In the present study, there was no significant survival benefit in the early excision group, but there was significant reduction in the length of stay and the cost of treatment.

The cost of treatment is one of the most important factors in the developing world and there are very few studies from India which have looked into the cost of burn care. ${ }^{15}$ Because of the fact that majority of the patients who sustain burn injuries are from the lower socioeconomic strata and are not covered under insurance, the cost of the burn treatment has to be borne by the government in the public hospitals or the patient and his or her family in private setups. In the study form a tertiary care government hospital in north India published in 2013, ${ }^{15}$ the authors showed that conservative burn treatment could be delivered with an average cost of INR 46,488 . In our study, we have estimated the mean cost of treating burn patients with early excision and grafting to be INR $100,837.50$, which was significantly lesser than late excision cases. This goes on to reiterate the feasibility of early excision and grafting of burns in resource poor countries.

This study is unique because there is a paucity of studies comparing timings of burn surgeries form the developing countries and this is the first of this type of study from this region. In this study, the authors have shown reductions in both the length of stay as well as the treatment cost in the early excision group, although the survival benefit could not be established statistically.

However, the authors acknowledge limitations of the study, namely, retrospective analysis of data, small sample size, noninclusion of morbidity of the patients like infections and graft loss in the study, and lack of long-term outcome of the patients. Because of the retrospective nature off the study, there is significant difference in the mean age of the early and late excision groups, which the authors will look into in the following studies. Further long-term studies will be required to establish the outcome in larger sample sizes and to establish the difference in the quality of life after early and late excision surgeries.

\section{Conclusion}

Early excision and grafting in burn cases reduce the length of the stay of burn patients and, in turn, reduce the cost of treatment. Early excision and grafting, if practiced in the hospitals of developing countries, will reduce the economic burden on the government exchequer and on individual patients and their families. However, having a dedicated burn care unit is important for the hospitals and both public and private hospitals should make a move in that direction.

\section{Conflict of Interest}

None.

\section{References}

1 Forjuoh SN. Burns in low- and middle-income countries: a review of available literature on descriptive epidemiology, risk factors, treatment, and prevention. Burns 2006;32(5):529-537

2 Janzekovic Z. A new concept in the early excision and immediate grafting of burns. J Trauma 1970;10(12):1103-1108 
3 Herndon DN, Barrow RE, Rutan RL, Rutan TC, Desai MH, Abston S. A comparison of conservative versus early excision. Therapies in severely burned patients. Ann Surg 1989;209(5):547-552

4 Thompson P, Herndon DN, Abston S, Rutan T. Effect of early excision on patients with major thermal injury. J Trauma 1987;27(2):205-207

5 Desai MH, Rutan RL, Herndon DN. Conservative treatment of scald burns is superior to early excision. J Burn Care Rehabil 1991;12(5):482-484

6 Subrahmanyam M. Early tangential excision and skin grafting of moderate burns is superior to honey dressing: a prospective randomised trial. Burns 1999;25(8):729-731

7 Engrav LH, Heimbach DM, Reus JL, Harnar TJ, Marvin JA. Early excision and grafting vs. nonoperative treatment of burns of indeterminant depth: a randomized prospective study. J Trauma 1983;23(11):1001-1004

8 Ong YS, Samuel M, Song C. Meta-analysis of early excision of burns. Burns 2006;32(2):145-150

9 Vinita P, Khare NA, Chandramouli M, Nilesh S, Sumit B. Comparative analysis of early excision and grafting vs delayed grafting in burn patients in a developing country. J Burn Care Res 2014;37(5):278-282

10 Gallaher JR, Mjuweni S, Shah M, Cairns BA, Charles AG. Timing of early excision and grafting following burn in sub-Saharan Africa. Burns 2015;41(6):1353-1359

11 Pietsch JB, Netscher DT, Nagaraj HS, Groff DB. Early excision of major burns in children: effect on morbidity and mortality. J Pediatr Surg 1985;20(6):754-757

12 Demling RH. Improved survival after massive burns. J Trauma 1983;23(3):179-184

13 Xiao-Wu W, Herndon DN, Spies M, Sanford AP, Wolf SE. Effects of delayed wound excision and grafting in severely burned children. Arch Surg 2002;137(9):1049-1054

14 Irei M, Abston S, Bonds E, Rutan T, Desai M, Herndon DN. The optimal time for excision of scald burns in toddlers. J Burn Care Rehabil 1986;7(6):508-510

15 Ahuja RB, Goswami P. Cost of providing inpatient burn care in a tertiary, teaching, hospital of North India. Burns 2013;39(4):558-564 